Article

\title{
Point-Defect-Rich Carbon Sheets as the High-Activity Catalyst Toward Oxygen Reduction and Hydrogen Evolution
}

\author{
Wenjing Yuan ${ }^{\dagger}$, Fuhua Zhang ${ }^{\dagger}$, Yaoyao Wu, Xiaotao Chen, Chihhsiang Fang and Chuanhao Li * \\ Guangdong Provincial Key Laboratory of Environmental Pollution Control and Remediation Technology, \\ School of Environmental Science and Engineering, Sun Yat-sen University, Guangzhou 510006, China; \\ yuanwj7@mail.sysu.edu.cn (W.Y.); zhangfh5@mail2.sysu.edu.cn (F.Z.); wuyy69@mail2.sysu.edu.cn (Y.W.); \\ chenxt68@mail2.sysu.edu.cn (X.C.); fangch29@mail2.sysu.edu.cn (C.F.) \\ * Correspondence: lichuanh3@mail.sysu.edu.cn \\ + These authors contributed equally to this work.
}

Received: 17 March 2019; Accepted: 18 April 2019; Published: 25 April 2019

\begin{abstract}
Exploring a novel approach for the synthesis of oxygen reduction reaction (ORR) and hydrogen evolution reaction (HER) catalysts with inexpensive and high-activity is desirable. Herein, we report a bubble templating method to synthesize the graphene-like mesoporous carbon sheets with point defects as ORR/HER bifunctional electrocatalysts. The typical product shows excellent ORR performance including the positive onset potential $(740 \mathrm{mV})$ and high diffusion-limiting current density $\left(4.07 \mathrm{~mA} \mathrm{~cm}^{-2}\right)$. Along with small Tafel slopes, the overpotential is determined to be about -453 and $-378 \mathrm{mV}$ at $10 \mathrm{~mA} \mathrm{~cm}{ }^{-2}$ in both alkaline and acidic media, which suggests a good candidate for HER reaction as well. The superior catalytic activities are derived from the abundant point defects on the mesoporous carbon sheets surface, especially the existence of pyridinic and pyrrolic nitrogen species. This study may be an alternative route to prepare the novel functional materials for the applications of ORR and HER.
\end{abstract}

Keywords: bubble templating approach; carbon defect; oxygen reduction; hydrogen evolution

\section{Introduction}

Developing renewable and green clean energy technologies in response to the increasingly serious energy crisis and environmental problem has attracted great attention of the scientific community [1-3]. The low catalysis efficiency of oxygen reduction and hydrogen evolution is the key bottleneck for the new energy conversion technologies in terms of proton exchange membrane fuel cell (PEMFC) and hydrogen production [4-6]. To accelerate the oxygen reduction reaction (ORR) and hydrogen evolution reaction (HER) kinetics, the introduction of platinum into catalyst is an effective means. Nevertheless, the expense and scarcity of resources hamper its industrial application [7-9]. Therefore, exploring a facile and low-cost synthetic process is of great significance to construct the highly-effective and resource-abundant electrocatalyst to replace the precious platinum-based materials.

Catalytic reactions occur on the surface of catalysts, and thus catalytic activity is largely dependent upon the surface conditions, such as area and defects. Increasing the surface area can improve the physical collision rate and generating surface defects can enhance the chemical interaction between the reactants and the surface of catalysts. Recently, graphene-like mesoporous carbon sheets as metal-free electrocatalysts have been broadly employed in the electrocatalytic ORR/HER process [10]. The unique graphene-like thin sheets and mesoporous structure leads to a high surface area, which is beneficial for $\mathrm{O}_{2}$ diffusion in ORR process [11], and water molecules adsorption during the HER process [12]. However, the electrocatalytic efficiency, especially for HER process, remains unsatisfactory. 
It is reasonable to introduce point defects on the surface of the above catalyst system for further enhancements. Point defects can not only effectively facilitate the oxygen adsorption and weaken the $\mathrm{O}-\mathrm{O}$ bonding to promote the ORR, but also significantly decrease the free energy of adsorbed $\mathrm{H}$ $\left(\Delta \mathrm{G}_{\mathrm{H}^{*}}\right)$ to enhance the proton/electron-transfer process $[13,14]$. Thus, it is extremely desired to explore a novel path for preparation of point-defect-rich graphene-like mesoporous carbon sheets.

Very recently, the bubble templating method has been widely used to porous materials $[15,16]$. Upon the calcination of thermovolatile materials, bubbles were in situ generated and served as a guiding agent for the growth of target materials. During the further heating process, the bubble was extruded or burst, generating porous structure. Herein, we utilized the bubble templating method to prepare the point-defect-rich graphene-like mesoporous carbon sheets. The schematic illustration of the construction process is presented in Scheme 1. Calcium gluconate is used as precursor materials. Abundant $\mathrm{CO}_{2}$ bubbles were generated during the calcination of calcium gluconate. After the bubble extrusion or burst process, the remaining carbon species present mesoporous sheet-like structure. The subsequent annealing process generates point defects. The details about experiment principle are presented in Supplementary Materials (see the formation mechanism of graphene-like mesoporous carbon sheets). The products exhibit excellent electrocatalytic ORR/HER activities regarding the onset potential, electron transfer number, measured $\mathrm{H}_{2} \mathrm{O}_{2}$ yield and overpotential. In addition, part of calcium sources converted into $\mathrm{CaCN}_{2}$ crystals dispersed on the surface of the carbon sheet, avoiding the agglomeration of carbon sheets, thus enhancing the stability of carbon sheets as the ORR/HER bifunctional electrocatalysts.

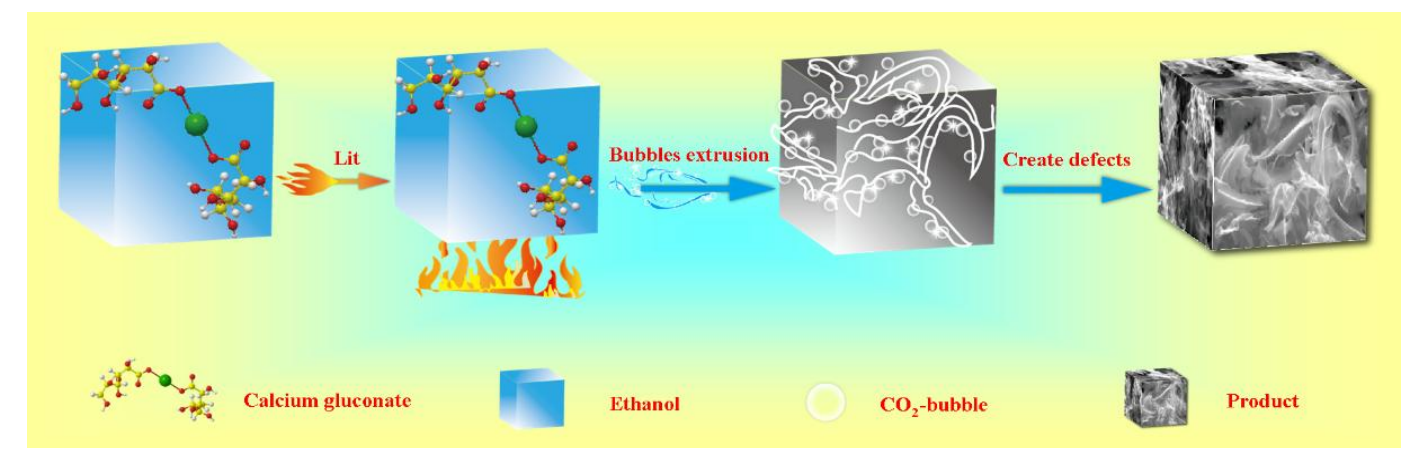

Scheme 1. Schematic illustration of formation mechanism of graphene-like mesoporous carbon sheets by $\mathrm{CO}_{2}$-bubble templating approach.

\section{Results}

Structural characteristics of all samples were revealed by X-ray diffraction (XRD) patterns as exhibited in Figure S1 (see the Supplementary Materials). As-prepared samples present a broad diffraction peak at around $22.0^{\circ}$, which can be assigned to the (002) diffraction plane of graphitic carbon [17]. The diffraction peaks of PDRC-900 (PDRC represents the point defects-rich carbon, while 900 corresponds to the annealing temperature.) and PDRC-1000 at bout 18.0, 30.4, 41.6 and $49.3^{\circ}$ can be belonged to the (003), (012), (015) and (110) planes of $\mathrm{CaCN}_{2}$ (JCPDS 32-0161). Scanning electron microscopy (SEM) and transmission electron microscopy (TEM) images (Figure 1a,b) show that the PDRC-1000 has a graphene-like carbon sheets and channel features, as well as in situ generated $\mathrm{CaCN}_{2}$ on the surface and interior of carbon sheets. A selected-area electron diffraction (SAED) (Figure 1b, inset) pattern derived from $\mathrm{CaCN}_{2}$ exhibits the single-crystalline nature. HRTEM image (Figure 1c) along the $<300>$ zone axis presents uniform lattice fringes, which are attributed to the (012) plane of $\mathrm{CaCN}_{2}$. Figure $1 \mathrm{~d}-\mathrm{i}$ show the elemental distribution of PDRC-1000, corresponding to the $\mathrm{C}, \mathrm{N}, \mathrm{O}$ and Ca elements, suggesting that the $\mathrm{N}$ atoms are introduced into the graphene-like carbon sheets surface to create the point defects and in situ growth of $\mathrm{CaCN}_{2}$. 

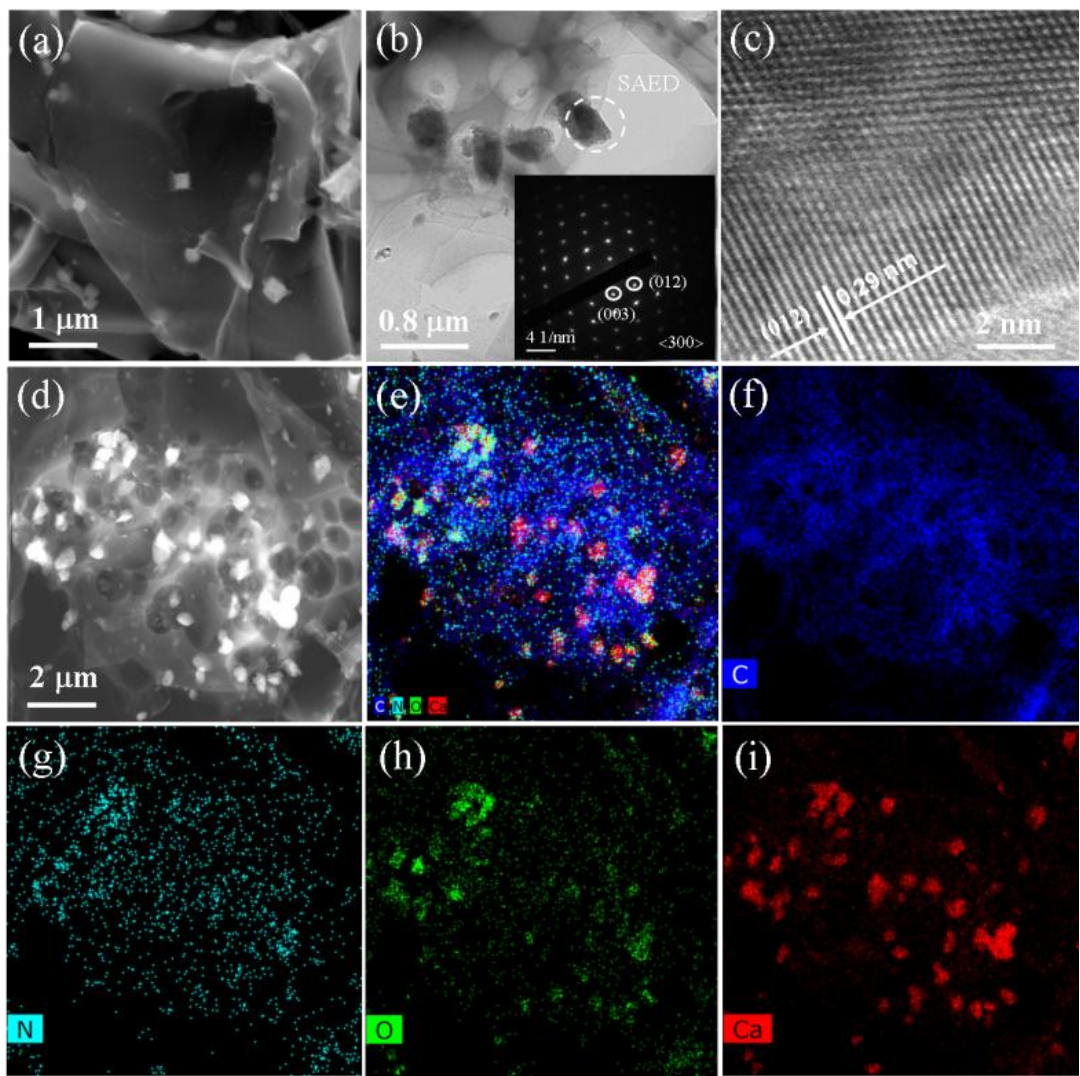

Figure 1. (a) Scanning electron microscopy, (b) transmission electron microscopy and the selected-area electron diffraction (inset), (c) high resolution transmission electron microscopy, (d) high-angle annular dark-field scanning transmission electron microscopy images and (e-i) elemental mapping of PDRC-1000.

The X-ray photoelectron spectroscopy (XPS) measurement was used to evaluate the composition of elements on the surface of samples in Figure S2 (see the Supplementary Materials). The XPS data clearly present the existence of $\mathrm{C}, \mathrm{O}, \mathrm{N}$ and $\mathrm{Ca}$ elements coming from as-obtained samples. The corresponding atomic ratio is shown in Table S1 (see the Supplementary Materials). Figure 2a-c show the XPS spectra of N1s of PDRC-800, PDRC-900 and PDRC-1000, which is well-divided into the peaks centered at bout 398.4, 399.9 and $401.3 \mathrm{eV}$, corresponding to the pyridinic $\mathrm{N}$, pyrrolic $\mathrm{N}$ and graphitic $\mathrm{N}[18,19]$. The schematic representation (Figure 2d) and contents of different $\mathrm{N}$-bond types in as-prepared products are obtained in Table S2 (see the Supplementary Materials). The pyridinic N and pyrrolic $\mathrm{N}$ are predominant than graphitic $\mathrm{N}$ in all samples, indicating its successful introduction of point defects by $\mathrm{NH}_{3}$ etching. Raman spectra (Figure S3, see the Supplementary Materials) of as-prepared products possess the prominent peaks at around 1350 and $1600 \mathrm{~cm}^{-1}$, which is associated with $\mathrm{D}$ and $\mathrm{G}$ peaks, corresponding to the disorder and defects, as well as the vibrational modes of $\mathrm{sp}^{2}$ carbon [20]. The ratio of the $\mathrm{D}$ and $\mathrm{G}$ peaks is used to quantify the level of the defect, where the values of about 1.521, 1.839, 1.939 and 1.725 for C-1000, PDRC-800, PDRC-900 and PDRC-1000, respectively, revealing that the introduction of nitrogen atoms can create the defects' structures in graphene-like carbon sheets [21]. 

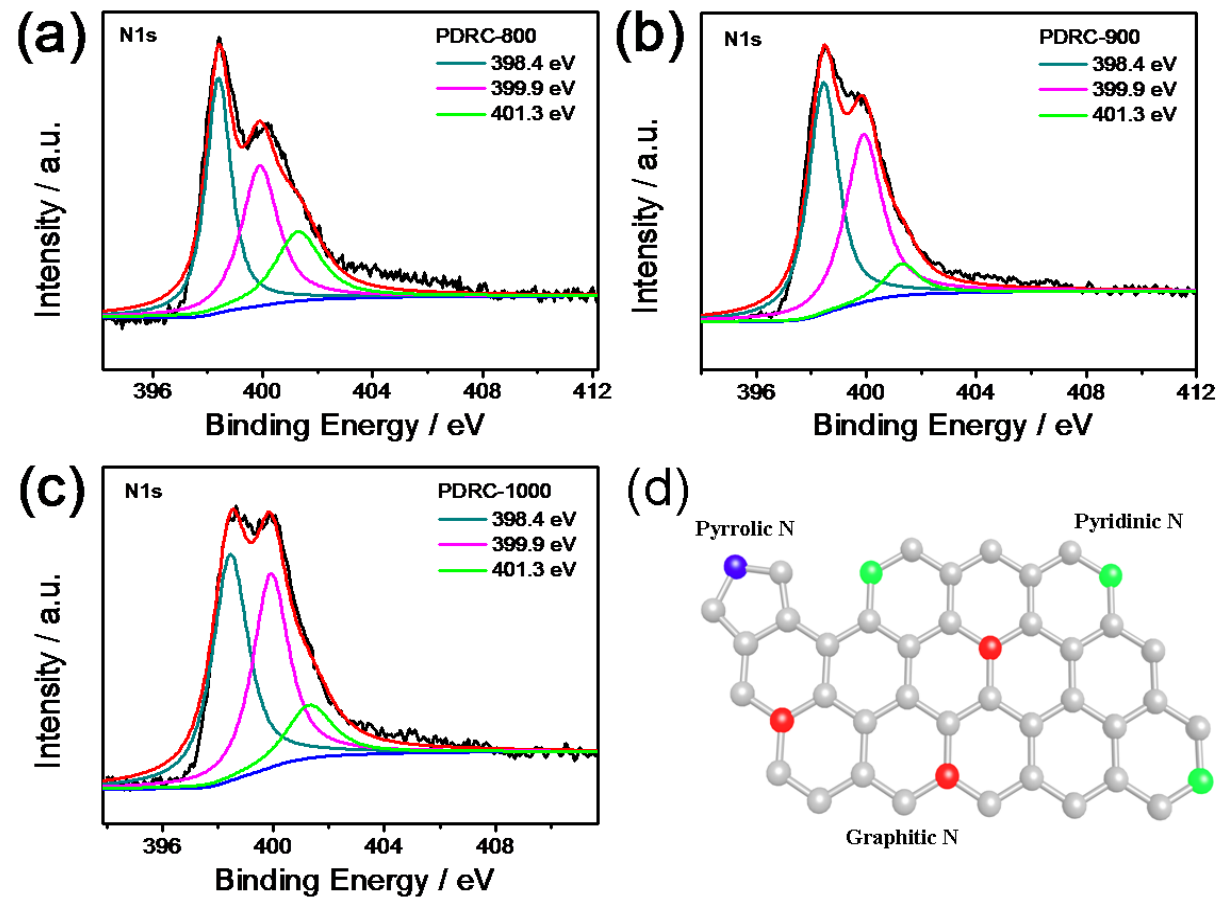

(d)

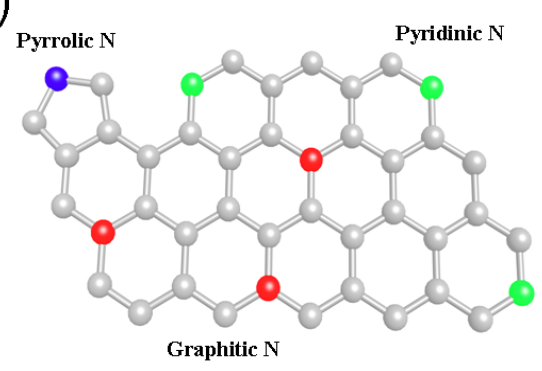

Figure 2. The N1s X-ray photoelectron spectra of (a) PDRC-800, (b) PDRC-900 and (c) PDRC-1000; (d) schematic representation of different $\mathrm{N}$-bond types in the graphitic plane.

Surface areas and porous features of catalysts were investigated by nitrogen adsorption-desorption isotherms' measurements. As shown in Figure 3a, the type-IV isotherms of all-prepared samples are obtained, indicating a mesoporous character. Interestingly, the PDRC-1000 display the highest surface area $\left(1158 \mathrm{~m}^{2} \mathrm{~g}^{-1}\right)$ compared to the C-1000 $\left(620 \mathrm{~m}^{2} \mathrm{~g}^{-1}\right)$, PDRC-800 $\left(809 \mathrm{~m}^{2} \mathrm{~g}^{-1}\right)$ and PDRC-900 $\left(1034 \mathrm{~m}^{2} \mathrm{~g}^{-1}\right)$, which may be due to the etching of $\mathrm{NH}_{3}$ atmosphere [22]. The pore size distributions of all-prepared samples are determined by the Barrett-Joyner-Halenda (BJH) method, and display the presence of abundant mesoporous characteristics with the pore size between 2.5 and $4.2 \mathrm{~nm}$ as shown in Figure 3b, which is beneficial for the transport of reactants and products in the ORR and HER process [23].
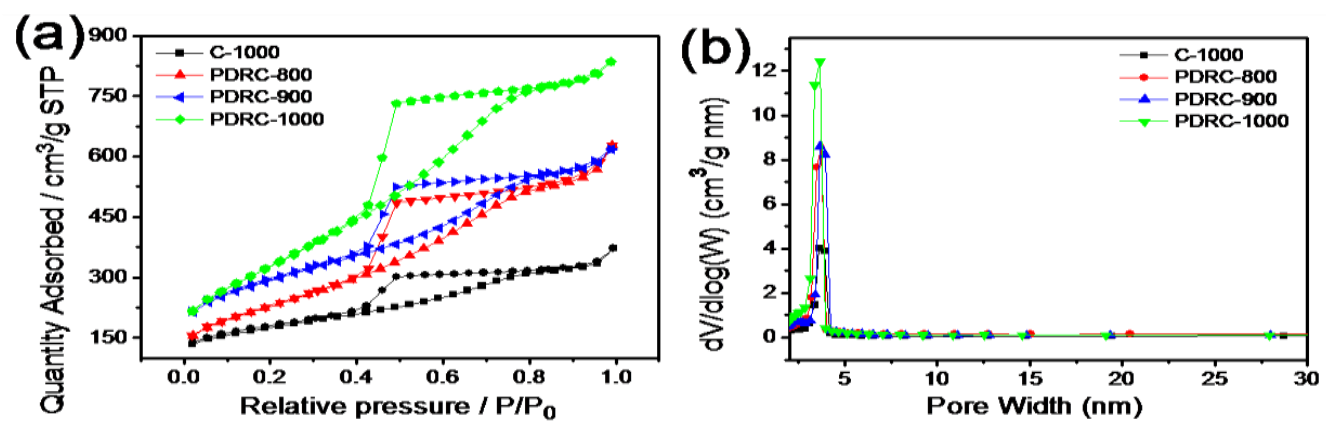

Figure 3. (a) Nitrogen adsorption-desorption isotherms and (b) pore size distributions of C-1000, PDRC-800, PDRC-900 and PDRC-1000.

The electrocatalytic ORR activities of as-prepared samples were analyzed by cyclic voltammetry (CV) cycles in the Ar or $\mathrm{O}_{2}$-saturated acidic media. From Figure S4 (see the Supplementary Materials), no obvious cathodic peaks from 1.0 to $0 \mathrm{~V}$ in Ar-saturated acidic media are observed for all products. In $\mathrm{O}_{2}$-saturated solution, the PDRC-1000 presents a cathodic peak at more positive potential than C-1000, PDRC-800 and PDRC-900. Rotating ring-disk electrode (RRDE) measurement was performed 
to evaluate the electron transfer number $(\mathrm{n})$ and $\mathrm{H}_{2} \mathrm{O}_{2}$ yield during the ORR process. The disk $\left(\mathrm{I}_{\mathrm{D}}\right)$ and ring $\left(I_{R}\right)$ currents of samples are recorded in acidic media as exhibited in Figure $4 a-b$ and Figure S5 (see the Supplementary Materials). The ORR electrocatalytic activity was highest with a PDRC-1000 sample for which a positive half-wave potential of $560 \mathrm{mV}$, an onset-potential of $740 \mathrm{mV}$ and a diffusion-limiting current density in RRDE voltammograms of $4.07 \mathrm{~mA} \mathrm{~cm}^{-2}$, respectively, compared to the C-1000, PDRC-800 and PDRC-900 under analogous conditions. For PDRC-1000 sample, the $n$ value and $\mathrm{H}_{2} \mathrm{O}_{2}$ yield were determined by Equations (1) and (2) (see the Supplementary Materials, Figure 4c,d) to be greater than 3.96 and lower than $1.66 \%$ between 0.30 to $0.01 \mathrm{~V}$, respectively. It indicates that PDRC-1000 is an efficient catalyst that follows a near four-electron ORR mechanism.
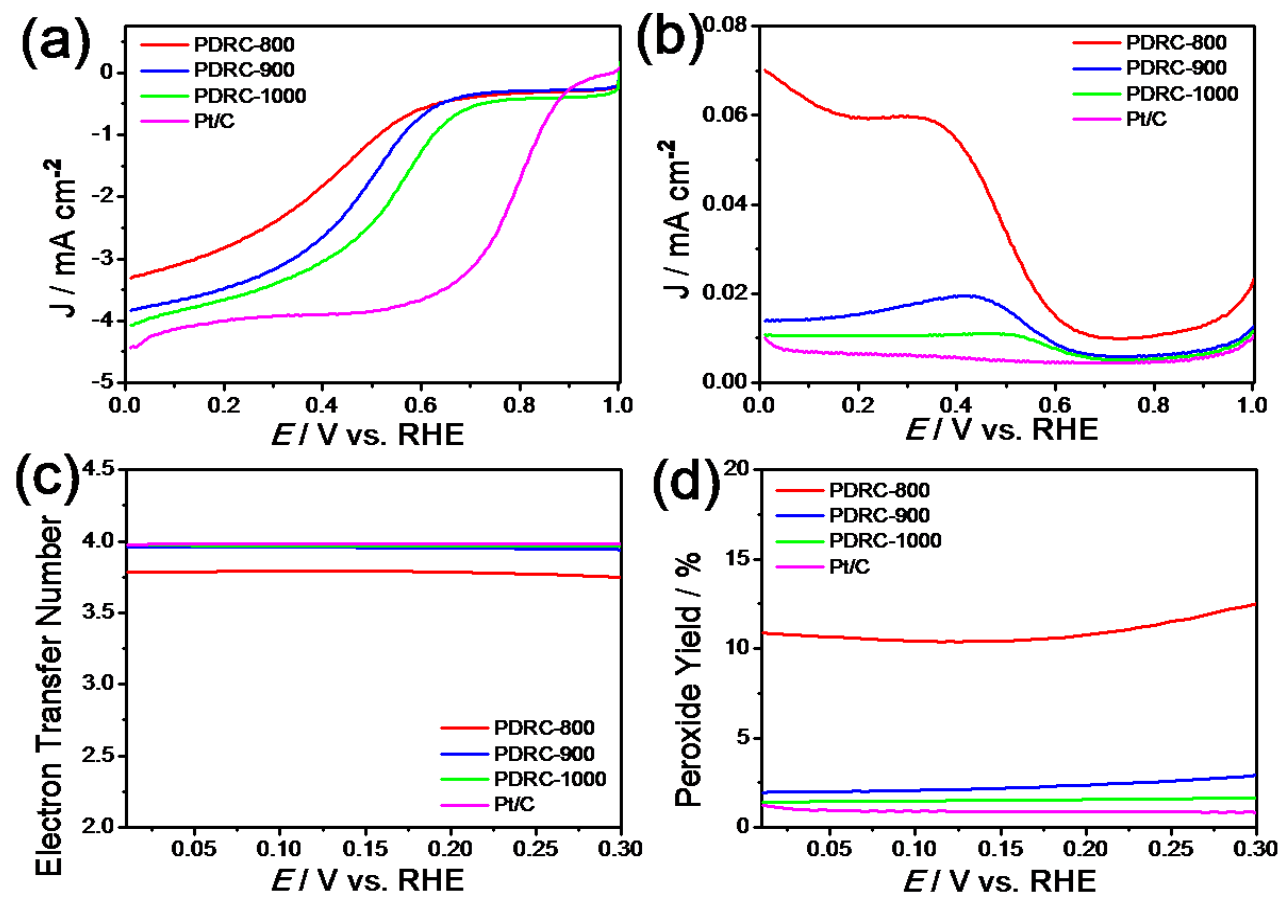

Figure 4. (a,b) RRDE voltammograms of PDRC-800, PDRC-900, PDRC-1000 and Pt/C in $\mathrm{O}_{2}$-saturated $0.5 \mathrm{M} \mathrm{H}_{2} \mathrm{SO}_{4}$; (c) the $n$ value and (d) $\mathrm{H}_{2} \mathrm{O}_{2}$ yield of PDRC-800, PDRC-900, PDRC-1000 and Pt/C.

From Figure 5a,b, the electrocatalytic HER activities of C-1000, PDRC-800, PDRC-900, PDRC-1000 and $\mathrm{Pt} / \mathrm{C}$ were investigated. Among all the as-prepared samples, the overpotentials at $10 \mathrm{~mA} \mathrm{~cm}{ }^{-2}$ of PDRC-1000 are $-453 \mathrm{mV}$ (in alkaline media) and $-378 \mathrm{mV}$ (in acidic media), which are more positive than C-1000, PDRC-800 and PDRC-900, revealing a low energy consumption in the electrocatalytic hydrogen production process. For in-depth study, the Tafel plots of PDRC samples derived from the corresponding polarization curves were investigated. The low Tafel slope of sample will result in a faster incrementation of hydrogen evolution reaction rate. From Figure $5 \mathrm{c}, \mathrm{d}$, the PDRC-1000 presents the lowest value of Tafel slope of about 109 (in alkaline media) and $103 \mathrm{mV}$ per decade in acidic media than the values of Tafel slopes for control samples, and close to that of $\mathrm{Pt} / \mathrm{C}$, revealing its decent electrocatalytic HER performance. 
$0.1 \mathrm{M} \mathrm{KOH}$

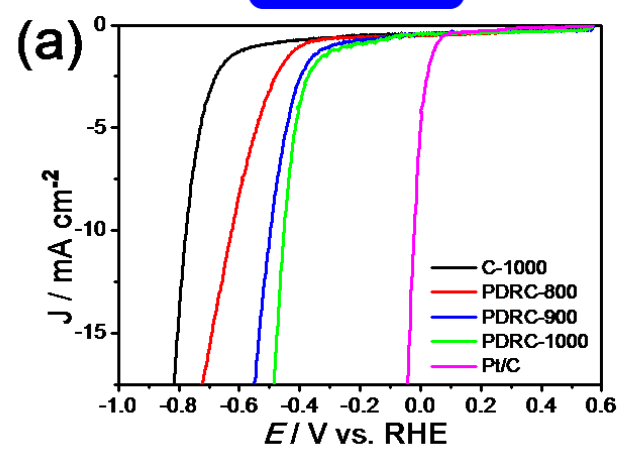

$0.1 \mathrm{M} \mathrm{KOH}$

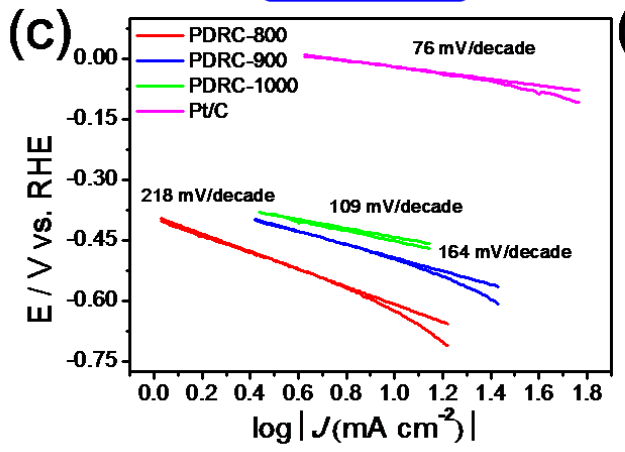

$0.5 \mathrm{M} \mathrm{H}_{2} \mathrm{SO}_{4}$

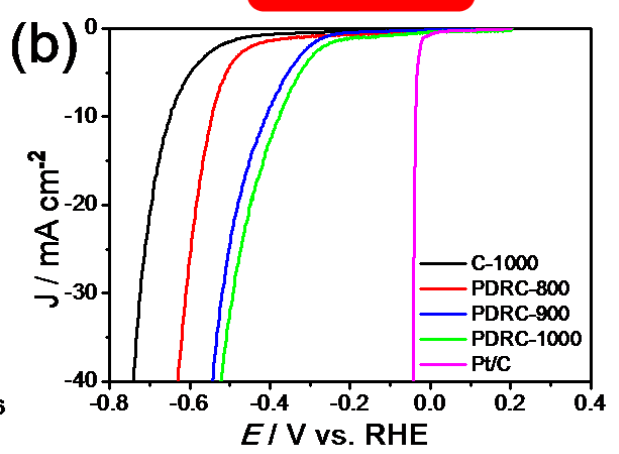

$0.5 \mathrm{M} \mathrm{H}_{2} \mathrm{SO}_{4}$

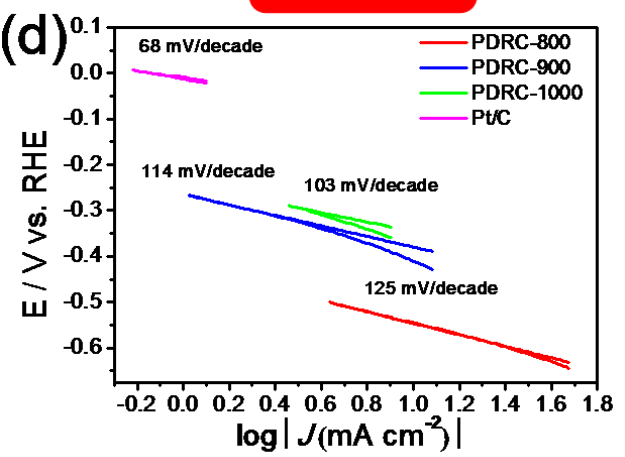

Figure 5. Polarization curves of C-1000, PDRC-800, PDRC-900, PDRC-1000 and Pt/C in (a) alkaline and (b) acidic media; Tafel plots of PDRC-800, PDRC-900, PDRC-1000 and Pt/C for HER in (c) alkaline and (d) acidic media, respectively.

In addition to excellent HER performance, the durability is another significant concern for its practical application in hydrogen production process, which was evaluated by chronoamperometry measurement. From Figure S6 (see the Supplementary Materials), i-t curves were recorded in both alkaline and acidic media, respectively. After 20 hours, the cathodic current density shows a small reduction from -1.77 to $-1.46 \mathrm{~mA} \mathrm{~cm}^{-2}$ in alkaline media, corresponding to the values from -1.20 to $-0.77 \mathrm{~mA} \mathrm{~cm}^{-2}$ in acidic media, confirming its decent durability in electrochemical hydrogen evolution process.

The electrocatalytic HER properties of PDRC-800, PDRC-900 and PDRC-1000 are associated with the resistance on interface between sample and electrolyte, and, hence, the electrochemical impedance spectroscopy (EIS) measurements were employed as presented in Figure 6. The PDRC-1000 has the smallest semicircle of Nyquist plots compared to the PDRC-800 and PDRC-900, revealing that the PDRC-1000 shows the best electron transfer ability for enhancing the HER kinetics.

The possible mechanisms for excellent ORR/HER activities of typical product may be originated from the following points. Firstly, the introduction of pyridinic $\mathrm{N}$ in graphene-like mesoporous carbon sheets create a large number of ORR active sites, as well as the $\mathrm{C}$ atom adjacent to pyridinic $\mathrm{N}$ in the initial step for adsorbed oxygen molecules [5]. Density functional theory display that the excellent HER performance derived from the reducing of $\Delta \mathrm{G}_{\mathrm{H}^{*}}$ of defects-rich structure [24]. The different electronegativities of different $\mathrm{N}$-bond types would adjust the electronic structures of adjacent $\mathrm{C}$ atoms in varying degrees, indicating its different $\Delta \mathrm{G}_{\mathrm{H}^{*}}$. The better electrocatalytic activity of pyrrolic $\mathrm{N}$ than that of the pyridinic $\mathrm{N}$ and graphitic $\mathrm{N}$ may be derived from the proper electronegativity and configuration after the introduction of point defects, which can enhance the $\mathrm{H}^{*}$ adsorption sites for improving the HER performance [25]. Secondly, the high BET surface area and mesoporous characters 
of sample are beneficial for the free diffusion of oxygen molecules ( $0.34 \mathrm{~nm}$ in kinetic diameter) and $\mathrm{H}_{2}$ detachment during the ORR and HER process [11]. Finally, the major active sites of typical product should be located in the graphene-like mesoporous carbon sheets with point defects-rich; however, the existence of $\mathrm{CaCN}_{2}$ can prevent the agglomeration of carbon sheets, which is also significant to expose the ORR and HER active sites.

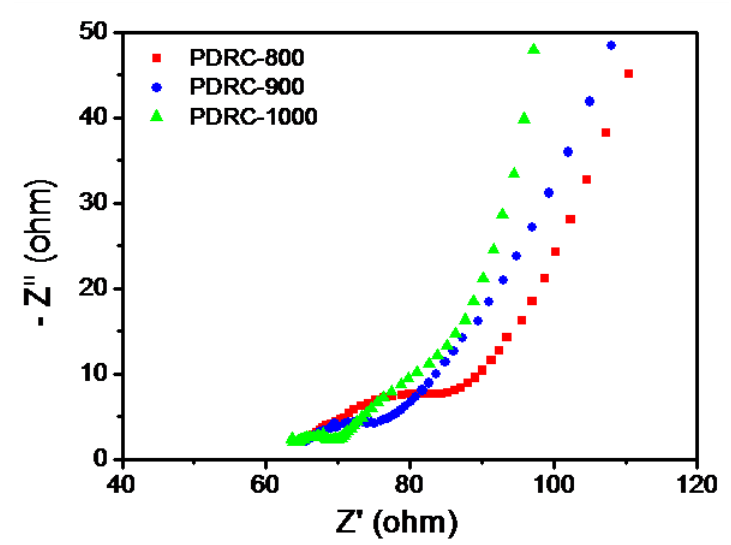

Figure 6. Electrochemical impedance spectroscopy (EIS) Nyquist plots of PDRC-800, PDRC-900 and PDRC-1000.

\section{Materials and Methods}

\subsection{Materials}

Calcium gluconate $\left(\mathrm{C}_{12} \mathrm{H}_{22} \mathrm{CaO}_{14}, 99.0 \%\right)$, ethanol $\left(\mathrm{C}_{2} \mathrm{H}_{6} \mathrm{O}, 99.7 \%\right)$ and hydrochloric acid $(\mathrm{HCl}$, $36.0 \%$ ) were purchased from Aladdin Industrial Corporation (Shanghai, China) and Guangzhou Chemical Reagent Factory (Guangzhou, China), respectively.

\subsection{Material Synthesis}

The point-defects-rich carbon sheets were constructed by $\mathrm{CO}_{2}$-bubble templating approach. In brief, $50 \mathrm{~g}$ of calcium gluconate was added to a beaker containing $40 \mathrm{~mL}$ of ethanol and stirred to form a mixture. Then, sponge-like carbon foam was formed by igniting the mixture. The carbon foam was then annealed at tube furnace in an $\mathrm{Ar}$ atmosphere at $600^{\circ} \mathrm{C}$ for $30 \mathrm{~min}$. The product was soaked into the hydrochloric acid and washed with distilled water. To generate point defects into porous carbon, the primary product was further annealed at tube furnace in an ammonia $\left(\mathrm{NH}_{3}\right)$ atmosphere at $1000{ }^{\circ} \mathrm{C}$ for one hour to obtain the typical sample, and marked as PDRC-1000, where PDRC and 1000 stand for the point defects-rich carbon and annealing temperature, respectively. The yield of the typical sample was about $10 \%$. Ammonia was used not only as the etching agent to increase the specific surface area, but also acts as nitrogen source to replace carbon atoms to create point defects. Control samples were synthesized using $800^{\circ} \mathrm{C}$ or $900^{\circ} \mathrm{C}$ by similar steps, which denoted as PDRC-800 and PDRC-900. Nitrogen-free sample was also synthesized by Ar atmosphere at $1000^{\circ} \mathrm{C}$, which was denoted as C-1000.

\subsection{Characterization}

The structural characteristics of all samples were revealed by an X-ray diffractometer (XRD, D-MAX 2200 VPC, RIGAKU, Neu-Isenburg, Germany). The microstructure and element distribution were analyzed through FEL Quanta 450 scanning electron microscope (SEM) and JEM-2100F transmission electron microscope (TEM, JEOL, Kyoto, Japan). The composition of elements on the surface of samples was evaluated via X-ray photoelectron spectrometer (XPS, ESCALAB 250Xi, Thermo, Waltham, MA, USA). Brunauer-Emmett-Teller (BET) surface area and Raman spectrum were revealed by micromeritics 
Tristar 3020 instrument and laser micro-Raman spectrometer (Renishaw inVia, Wotto-under-Edge, UK), respectively.

\subsection{Electrochemical Measurements}

ORR performance was analyzed via an electrochemical workstation (Wavedrive 20, Pine Instrument Co., Ltd., Grove City, PA, USA) combined with a RRDE system with diameter of $5.61 \mathrm{~mm}$. Meanwhile, the reference electrode is $\mathrm{Ag} / \mathrm{AgCl}$, while graphite rod served as the counter electrode. $8.0 \mathrm{mg}$ of product in $2.0 \mathrm{~mL}$ ethanol to form the catalyst or $\mathrm{Pt} / \mathrm{C}(20 \%$, Johnson Matthey, London, UK) ink (4 mg mL $\left.\mathrm{mL}^{-1}\right)$ via ultrasonically was obtained. Subsequently, the RRDE electrode surface was dripped with $10 \mu \mathrm{L}$ of catalyst or $\mathrm{Pt} / \mathrm{C}$ ink and then adhered with Nafion solution $(10 \mu \mathrm{L}$, $0.05 \mathrm{wt} \%$ ), and followed by drying. ORR tests were implemented in $\mathrm{Ar}$ or $\mathrm{O}_{2}$-saturated $0.5 \mathrm{M} \mathrm{H}_{2} \mathrm{SO}_{4}$.

HER performance was evaluated through an electrochemical workstation (Gamry, reference 3000, Warminster, PA, USA) with a three-electrode system equipped with a graphite rod, an $\mathrm{Ag} / \mathrm{AgCl}$ and a glassy carbon with diameter of $3 \mathrm{~mm}$. In the same manner, the glassy carbon electrode surface was dripped with $5 \mu \mathrm{L}$ of catalyst or $\mathrm{Pt} / \mathrm{C}$ ink $\left(4 \mathrm{mg} \mathrm{mL}^{-1}\right)$ and then adhered with Nafion solution $(5 \mu \mathrm{L}$, $0.05 \mathrm{wt} \%)$, and followed by drying. The HER activities of as-prepared samples were determined in $0.1 \mathrm{M} \mathrm{KOH}$ or $0.5 \mathrm{M} \mathrm{H}_{2} \mathrm{SO}_{4}$, respectively. All potentials were iR-compensated.

\section{Conclusions}

In summary, we report the design and construction of graphene-like mesoporous carbon sheets through a new approach assisted by a $\mathrm{CO}_{2}$-bubble templating approach. After the introduction of point defects into mesoporous carbon sheets, more active sites are created for electrochemical reactions. As a result, the typical product exhibits outstanding ORR and HER activities, as well as excellent durability in both alkaline and acidic media during the HER process, indicating it an ideal candidate for the application of PEMFC and hydrogen production. This study opens a novel method to use the $\mathrm{CO}_{2}$-bubbles extrusion to prepare graphene-like mesoporous carbon sheets for electrochemical energy applications.

Supplementary Materials: The following are available online at http://www.mdpi.com/2073-4344/9/4/386/s1, Figure S1: title, Table S1: title, Video S1: title. Figure S1. XRD patterns of C-1000, PDRC-800, PDRC-900 and PDRC-1000, Figure S2. XPS data of PDRC-800, PDRC-900 and PDRC-1000, Figure S3. Raman spectra of (a) C-1000, (b) PDRC-800, (c) PDRC-900 and (d) PDRC-1000, Figure S4. CV curves of (a) C-1000, (b) PDRC-800, (c) PDRC-900 and (d) PDRC-1000 (scan rate $150 \mathrm{mV} \mathrm{s}^{-1}$ ) in $\mathrm{Ar}$ - or $\mathrm{O}_{2}$-saturated $0.5 \mathrm{M} \mathrm{H}_{2} \mathrm{SO}_{4}$, Figure S5. (a) RRDE voltammograms, (b) the $n$ value and (c) $\mathrm{H}_{2} \mathrm{O}_{2}$ yield of C-1000 in $\mathrm{O}_{2}$-saturated $0.5 \mathrm{M} \mathrm{H}_{2} \mathrm{SO}_{4}$, Figure S6. The stability measurements of PDRC-1000 electrode over $20 \mathrm{~h}$ in (a) alkaline and (b) acidic media, respectively, Table S1. The atomic $\%$ of C, O, N and Ca of samples from XPS data, Table S2. The atomic $\%$ of the different $\mathrm{N}$-bond types from XPS data, Table S3. The summary table of the samples used and their main properties.

Author Contributions: Conceptualization, W.Y.; synthesis, W.Y. and F.Z.; characterizations, electrochemical measurements, and data analysis, W.Y., F.Z., Y.W., X.C., and C.F.; supervision, C.L.; writing and discussion, W.Y., F.Z., Y.W., X.C, C.F., and C.L.

Funding: This research was funded by the National Natural Science Foundation of China (21876213), Science and Technology Program of Guangzhou (201804010261), China Postdoctoral Science Foundation (2018M643311) and the Research Fund Program of Guangdong Provincial Key Laboratory of Environmental Pollution Control and Remediation Technology (2018K11).

Acknowledgments: The authors would like to thank Xianfeng Yang at the South China University of Technology for HRTEM and EDX mapping characterizations.

Conflicts of Interest: The authors declare no conflict of interest.

\section{References}

1. Nong, S.; Dong, W.; Yin, J.; Dong, B.; Lu, Y.; Yuan, X.; Wang, X.; Bu, K.; Chen, M.; Jiang, S.; et al. Well-Dispersed Ruthenium in Mesoporous Crystal $\mathrm{TiO}_{2}$ as an Advanced Electrocatalyst for Hydrogen Evolution Reaction. J. Am. Chem. Soc. 2018, 140, 5719-5727. [CrossRef] [PubMed] 
2. Feng, J.-X.; Tong, S.-Y.; Tong, Y.-X.; Li, G.-R. Pt-like Hydrogen Evolution Electrocatalysis on PANI/CoP Hybrid Nanowires by Weakening the Shackles of Hydrogen Ions on the Surfaces of Catalysts. J. Am. Chem. Soc. 2018, 140, 5118-5126. [CrossRef] [PubMed]

3. Pan, Y.; Sun, K.; Liu, S.; Cao, X.; Wu, K.; Cheong, W.-C.; Chen, Z.; Wang, Y.; Li, Y.; Liu, Y.; et al. Core-Shell ZIF-8@ZIF-67-Derived CoP Nanoparticle-Embedded N-Doped Carbon Nanotube Hollow Polyhedron for Efficient Overall Water Splitting. J. Am. Chem. Soc. 2018, 140, 2610-2618. [CrossRef]

4. Chung, H.T.; Cullen, D.A.; Higgins, D.; Sneed, B.T.; Holby, E.F.; More, K.L.; Zelenay, P. Direct Atomic-Level Insight into the Active Sites of a High-Performance PGM-Free ORR Catalyst. Science 2017, 357, 479-483. [CrossRef]

5. Guo, D.; Shibuya, R.; Akiba, C.; Saji, S.; Kondo, T.; Nakamura, J. Active Sites of Nitrogen-Doped Carbon Materials for Oxygen Reduction Reaction Clarified using Model Catalysts. Science 2016, 351, 361-365. [CrossRef]

6. Li, K.; Li, Y.; Wang, Y.; Ge, J.; Liu, C.; Xing, W. Enhanced Electrocatalytic Performance for the Hydrogen Evolution Reaction through Surface Enrichment of Platinum Nanoclusters Alloying with Ruthenium in Situ Embedded in Carbon. Energy Environ. Sci. 2018, 11, 1232-1239. [CrossRef]

7. Bu, L.; Zhang, N.; Guo, S.; Zhang, X.; Li, J.; Yao, J.; Wu, T.; Lu, G.; Ma, J.-Y.; Su, D.; et al. Biaxially Strained $\mathrm{PtPb} / \mathrm{Pt}$ Core/Shell Nanoplate Boosts Oxygen Reduction Catalysis. Science 2016, 354, 1410-1414. [CrossRef] [PubMed]

8. $\quad$ Li, M.; Zhao, Z.; Cheng, T.; Fortunelli, A.; Chen, C.-Y.; Yu, R.; Zhang, Q.; Gu, L.; Merinov, B.V.; Lin, Z.; et al. Ultrafine Jagged Platinum Nanowires Enable Ultrahigh Mass Activity for the Oxygen Reduction Reaction. Science 2016, 354, 1414-1419. [CrossRef] [PubMed]

9. Ma, Y.-Y.; Wu, C.-X.; Feng, X.-J.; Tan, H.-Q.; Yan, L.-K.; Liu, Y.; Kang, Z.-H.; Wang, E.-B.; Li, Y.-G. Highly Efficient Hydrogen Evolution from Seawater by a Low-Cost and Stable CoMoP@C Electrocatalyst Superior to Pt/C. Energy Environ. Sci. 2017, 10, 788-798. [CrossRef]

10. Xu, Q.; Tang, Y.; Zhang, X.; Oshima, Y.; Chen, Q.; Jiang, D. Template Conversion of Covalent Organic Frameworks into 2D Conducting Nanocarbons for Catalyzing Oxygen Reduction Reaction. Adv. Mater. 2018, 30, 1706330. [CrossRef]

11. Jiang, W.-J.; Hu, J.-S.; Zhang, X.; Jiang, Y.; Yu, B.-B.; Wei, Z.-D.; Wan, L.-J. In Situ Nitrogen-Doped Nanoporous Carbon Nanocables as an Efficient Metal-Free Catalyst for Oxygen Reduction Reaction. J. Mater. Chem. A 2014, 2, 10154-10160. [CrossRef]

12. Huang, X.; Zhao, Y.; Ao, Z.; Wang, G. Micelle-Template Synthesis of Nitrogen-Doped Mesoporous Graphene as an Efficient Metal-Free Electrocatalyst for Hydrogen Production. Sci. Rep. 2014, 4, 7557. [CrossRef]

13. Zhu, C.; Li, H.; Fu, S.; Du, D.; Lin, Y. Highly Efficient Nonprecious Metal Catalysts towards Oxygen Reduction Reaction based on Three-Dimensional Porous Carbon Nanostructures. Chem. Soc. Rev. 2016, 45, 517-531. [CrossRef] [PubMed]

14. Li, J.-S.; Wang, Y.; Liu, C.-H.; Li, S.-L.; Wang, Y.-G.; Dong, L.-Z.; Dai, Z.-H.; Li, Y.-F.; Lan, Y.-Q. Coupled Molybdenum Carbide and Reduced Graphene Oxide Electrocatalysts for Efficient Hydrogen Evolution. Nat. Commun. 2016, 7, 11204. [CrossRef]

15. Xu, H.; Feng, J.-X.; Tong, Y.-X.; Li, G.-R. Cu ${ }_{2} \mathrm{O}-\mathrm{Cu}$ Hybrid Foams as High-Performance Electrocatalysts for Oxygen Evolution Reaction in Alkaline Media. Acs Catal. 2017, 7, 986-991. [CrossRef]

16. Liu, L.; Chen, L.-X.; Wang, A.-J.; Yuan, J.; Shen, L.; Feng, J.-J. Hydrogen Bubbles Template-Directed Synthesis of Self-Supported AuPt Nanowire Networks for Improved Ethanol Oxidation and Oxygen Reduction Reactions. Int. J. Hydrogen Energy 2016, 41, 8871-8880. [CrossRef]

17. Liu, X.; Zhou, Y.; Zhou, W.; Li, L.; Huang, S.; Chen, S. Biomass-Derived Nitrogen Self-Doped Porous Carbon as Effective Metal-Free Catalysts for Oxygen Reduction Reaction. Nanoscale 2015, 7, 6136-6142. [CrossRef]

18. Gao, S.; Geng, K.; Liu, H.; Wei, X.; Zhang, M.; Wang, P.; Wang, J. Transforming Organic-Rich Amaranthus Waste into Nitrogen-Doped Carbon with Superior Performance of the Oxygen Reduction Reaction. Energy Environ. Sci. 2015, 8, 221-229. [CrossRef]

19. Zhang, P.; Sun, F.; Xiang, Z.; Shen, Z.; Yun, J.; Cao, D. ZIF-Derived in Situ Nitrogen-Doped Porous Carbons as Efficient Metal-Free Electrocatalysts for Oxygen Reduction Reaction. Energy Environ. Sci. 2014, 7, 442-450. [CrossRef] 
20. Panomsuwan, G.; Saito, N.; Ishizaki, T. Nitrogen-Doped Carbon Nanoparticle-Carbon Nanofiber Composite as an Efficient Metal-Free Cathode Catalyst for Oxygen Reduction Reaction. ACS Appl. Mater. Interface 2016, 8, 6962-6971. [CrossRef]

21. Zhang, S.; Cai, Y.; He, H.; Zhang, Y.; Liu, R.; Cao, H.; Wang, M.; Liu, J.; Zhang, G.; Li, Y.; et al. Heteroatom Doped Graphdiyne as Efficient Metal-Free Electrocatalyst for Oxygen Reduction Reaction in Alkaline Medium. J. Mater. Chem. A 2016, 4, 4738-4744. [CrossRef]

22. Chen, P.; Wang, L.-K.; Wang, G.; Gao, M.-R.; Ge, J.; Yuan, W.-J.; Shen, Y.-H.; Xie, A.-J.; Yu, S.-H. Nitrogen-Doped Nanoporous Carbon Nanosheets Derived from Plant Biomass: An Efficient Catalyst for Oxygen Reduction Reaction. Energy Environ. Sci. 2014, 7, 4095-4103. [CrossRef]

23. Zhang, J.; Song, Y.; Kopec, M.; Lee, J.; Wang, Z.; Liu, S.; Yan, J.; Yuan, R.; Kowalewski, T.; Bockstaller, M.R.; et al. Facile Aqueous Route to Nitrogen-Doped Mesoporous Carbons. J. Am. Chem. Soc. 2017, 139, 12931-12934. [CrossRef] [PubMed]

24. Ito, Y.; Cong, W.; Fujita, T.; Tang, Z.; Chen, M. High Catalytic Activity of Nitrogen and Sulfur Co-Doped Nanoporous Graphene in the Hydrogen Evolution Reaction. Angew. Chem. Int. Ed. 2015, 54, 2131-2136. [CrossRef] [PubMed]

25. Yang, Y.; Lun, Z.; Xia, G.; Zheng, F.; He, M.; Chen, Q. Non-Precious Alloy Encapsulated in Nitrogen-Doped Graphene Layers Derived from MOFs as an Active and Durable Hydrogen Evolution Reaction Catalyst. Energy Environ. Sci. 2015, 8, 3563-3571. [CrossRef]

(C) 2019 by the authors. Licensee MDPI, Basel, Switzerland. This article is an open access article distributed under the terms and conditions of the Creative Commons Attribution (CC BY) license (http://creativecommons.org/licenses/by/4.0/). 